\author{
$\stackrel{\odot}{ }$

\section{MODA I HIPSTERSTWO. HIERARCHIE STATUSU WE WSPÓŁCZESNYM SPOŁECZEŃSTWIE KONSUMPCYJNYM}

\begin{abstract}
Iwasiński, Moda i hipsterstwo. Hierarchie statusu we współczesnym społeczeństwie konsumpcyjnym [Fashion and Hip. Status Hierarchies in Contemporary Consumer Societies], edited by M. Baranowski, „CZłowiek i Społeczeństwo”, vol. XL, Poznań 2015, pp. 177-195, Adam Mickiewicz University Press. ISBN 978-83-232-2964-3, ISSN 0239-3271.

Consumption in sociology is often considered a manifestation of status. According to Pierre Bourdieu, individuals determined by habitus and class dispositions, by consuming certain goods and the style of consumption, consciously or not, demonstrate their status. Bourdieu recognized the uniform hierarchy of status derived from a class structure. Today, this perspective is contested. It is difficult to reconcile it with theories stating class dehierarchization and individualization of society, especially with postmodern concepts. This does not mean that consumer behaviors lost its distinctive function. However, the criteria of distinction (and therefore the source of the status hierarchy) do not necessarily have a class background. In today's world they are more relativized, more ephemeral and determined by cultural factors. The article examines the source of the status hierarchy in contemporary consumer societies, indicating the role of fashion and the phenomenon of "hip" ("cool").

Łukasz Iwasiński, Uniwersytet Warszawski, Zakład Systemów Informacyjnych, Instytut Informacji Naukowej i Studiów Bibliologicznych, ul. Nowy Świat 69, 00-927 Warszawa, e-mail: lukiwas@gmail. com
\end{abstract}

Konsumpcja bywa ujmowana jako manifestacja statusu. Optykę tę na gruncie nauk społecznych rozwijali przede wszystkim Thorstein Veblen ${ }^{1}$ i Pierre Bourdieu². Pierwszy z nich na przełomie XIX i XX wieku zaini-

${ }^{1}$ T. Veblen, Teoria klasy próżniaczej, Warszawa 2008.

2 P. Bourdieu, Dystynkcja. Społeczna krytyka władzy sq̨dzenia, Warszawa 2005. 
cjował badania i refleksję nad formami ostentacyjnej konsumpcji, a więc konsumpcją jako świadomą rywalizacją statusową. Późniejsza, opracowana w latach 70. XX wieku, znacznie bardziej wyrafinowana teoria Bourdieu koncentruje się raczej na tym, w jaki sposób dzięki społecznie (a konkretnie: klasowo) wytworzonym regułom klasyfikacji konsumenci manifestują swój status nieświadomie. A zatem w perspektywie Bourdieu hierarchię statusu społecznego wyznacza struktura klasowa, a styl konsumpcji jest pochodną usytuowania w tej strukturze. Koherentne (zgodnie z zasadą homologii), charakterystyczne dla przedstawicieli danej klasy przedmioty i style konsumpcji komunikują ich status, odróżniając od członków innych klas. Ta perspektywa jest dziś podważana, gdyż trudno ją pogodzić z teoriami głoszącymi klasową dehierarchizację i indywidualizację społeczeństwa, a zwłaszcza z koncepcjami postmodernistycznymi. Nie oznacza to, że zachowania konsumpcyjne przestały pełnić funkcję dystynktywną. Jednak kryteria owej dystynkcji (a zatem źródła hierarchii statusu) niekoniecznie mają charakter klasowy. We współczesnym świecie ulegają one relatywizacji, stają się bardziej efemeryczne i uwarunkowane przede wszystkim kulturowo.

\section{Moda}

We współczesnych kapitalistycznych społeczeństwach można wskazać kulturowe trendy w znaczący sposób kształtujące styl konsumpcji ich członków, przekraczające klasowo określone hierarchie ${ }^{3}$. Moda na ekologię łączy anarchizującą młodzież i profesorów uniwersytetu ${ }^{4}$, popkulturowych celebrytów, z których wielu propaguje proekologiczne zachowania, jak i członków amerykańskiej rodziny prezydenckiej (jak donosi „Gazeta Wyborcza”: „W marcu Michelle Obama posadziła pierwsze warzywa w swoim ekoogródku na tyłach Białego Domu”5). Jak pisze Geoffrey Miller: „Nawet współczesna burżuazyjna bohema ${ }^{6}$ wspiera dziś odnawialność środowiska,

${ }^{3}$ Por. M. Krajewski, Konsumpcja i współczesność. O pewnej perspektywie rozumienia świata społecznego, „Kultura i Społeczeństwo” 3/1997, s. 15.

${ }^{4}$ K. Domagalska, Ekolodzy schodzq z drzew, „Wysokie Obcasy” z 7.13.2010 r., http:// www.wysokieobcasy.pl/wysokie-obcasy/1,80530,8116701,Ekolodzy_schodza_z_drzew. html [10.11.2014].

${ }^{5}$ K. Bosacka, Bracia od czekolady i siostry od sera, „Wysokie Obcasy” z 12.07 .2009 r., http://www.wysokieobcasy.pl/wysokie-obcasy/1,80530,6806589.html [10.11.2014].

${ }^{6}$ Powstała na początku XXI wieku kategoria socjologiczna określająca przedstawicieli zachodnich społeczeństw, którzy łączą etos pracy i przedsiębiorczości wywiedzione z lat 80. z kultem wolności w duchu lat 60., zamiłowanie do pieniędzy i lewicowe hasła, 
dobrowolną prostotę, świadome życie, uprawy organiczne, społeczną odpowiedzialność korporacji i próbuje przywrócić pewne aspekty ekoprymitywizmu wspólnotowego do swoich grodzonych osiedli"7.

Taki trend szybko zostaje przechwycony i wzmocniony przez rynek, przeradzając się w całościowy styl życia. Pojawia się bogata oferta dóbr i usług go wspierających (pod jego szyldem sprzedawać można choćby: ekologiczną żywność, ubranie, wyposażenie mieszkania i inne przedmioty użytkowe, ekologiczne wakacje i sposoby spędzania czasu). Serwis egospodarka.pl pisze:

W krajach takich jak Polska rynek żywności ekologicznej jest jednym z najszybciej rosnących segmentów rynku rolno-spożywczego. Wielu konsumentów uwierzyło pod wpływem kampanii reklamowych, że żywność ekologiczna, czyli produkowana tradycyjnymi metodami, bez użycia nawozów sztucznych, jest lepsza i zdrowsza od konwencjonalnej ${ }^{8}$.

W innym artykule czytamy:

Termin eko dodaje się dziś do wszystkiego. Są ekotrumny, ekojaja, ekoodkurzacze, a także futra, meble, papier toaletowy, torby na zakupy. Mamy ekologiczne stacje benzynowe, pralnie i gotowe do akcji i demonstracji ekologiczne organizacje. Są ekologiczne, szybko biodegradowalne prezerwatywy, ekologiczne bułki z „biologiczną” mąką, ba - pokazała się nawet ekologiczna wódka9 .

Na przykład firma Zielone Biuro reklamuje się w następujący sposób:

W naszym asortymencie można znaleźć użytkowe gadżety ekologiczne, poczynając od długopisu ze skrobi kukurydzianej, a kończąc na samochodzie napędzanym energią słoneczną. Multum wspaniałych ekologicznych gadżetów reklamowych oraz przyjaznych środowisku przedmiotów biurowych czeka na odkrycie! Kolejnym polem naszej działalności jest ekologiczna

pragmatyzm i artystyczne inklinacje, cenią komfort, sukces, ale bliska jest im także społeczna odpowiedzialność; nie chcą być, niczym yuppie, wewnętrznie puści. Można rzec, że są oni owocem oswojenia przez popkulturę i zagospodarowania przez rynek emancypacyjno-lewicowej retoryki, przekroczenia opozycji między wartościami kapitalizmu a kontrkultury. Zob. D. Brooks, Bobos in Paradise: The New Upper Class and How They Got There, New York 2000.

${ }^{7}$ G. Miller, Teoria szpanu. Seks ewolucja i zachowanie klienta, Warszawa 2010, s. 18.

${ }^{8}$ http://www.firma.egospodarka.pl/43423,Czy-zywnosc-ekologiczna-rozni-sie-od-zwyklej,1,11,1.html [10.11.2014].

${ }_{9}^{9}$ http://edunews.pl/index.php?option=com_content\&task=view\&id=904\&Itemid=16 [10.11.2014]. 
poligrafia. Wszelkie ulotki, wizytówki, papier biurowy, koperty, zakładki do książek itd. możemy zapewnić w wydaniu ekologicznym ${ }^{10}$.

Z kolei firma Jolankom oferuje „ekologię dla domu i ogrodu”11, zaś Organic Farma Zdrowia to „pierwsza i największa w Polsce sieć samoobsługowych delikatesów z ekologiczną i zdrową żywnością, kosmetykami i środkami czyszcząco-piorącymi” ${ }^{12}$. Co prawda często owe produkty i usługi z rzeczywistą ekologią nie mają wiele wspólnego, są jedynie na ekologiczne stylizowane, tym samym stanowią formę - jak pisze Anna Nacher - „ekokiczu” "13 bądź - jak ujmuje to Agata Neale - „ekobubla” ${ }^{14}$. Nie interesuje mnie tu jednak istnienie bądź nie faktycznych proekologicznych właściwości promowanych w ten sposób produktów, lecz wskazanie, że ekologia stała się modą, która kształtuje kryteria dystynkcji i wzory konsumpcji. Jak pisze Felicjan Bylok:

Moda jest instrumentem przekazu kulturowego, nadaje nowe lub zmienia stare znaczenia kulturowe dobrom konsumpcyjnym. Wyznacza też kierunek zmian w sferze konsumpcji, stając się ważnym czynnikiem pobudzającym określone zachowania konsumpcyjne ${ }^{15}$.

Stanowi „kod albo język, który pomaga odszyfrować znaczenie danego dobra konsumpcyjnego"16, a także identyfikuje społecznie jego użytkownika. Ekologia to niewątpliwie jeden z nośnych trendów czy też mód ${ }^{17}$ we współczesnej kulturze, który wytwarza określone normy i kształtuje dyspozycje swych zwolenników. Manifestuje się on poprzez konsumpcję takich a nie innych dóbr, jak i całościowy, homologiczny proekologiczny styl życia. Stąd można dziś mówić o ekokonsumpcji (fenomen ten odnotowują także polscy

10 http://www.zielonebiuro.com/ [10.11.2014].

11 http://www.jolankom.pl.tl/ [10.11.2014].

12 http://www.organicmarket.pl/spoka.html [10.11.2014].

13 A. Nacher, Rubieże kultury popularnej, Kraków 2012, ss. 146-174.

14 A. Neale, (Nie)przyjemności zielonego konsumeryzmu, w: K. Romaniszyn (red.), Nowa droga do zniewolenia. O życiu w społeczeństwie konsumpcyjnym, Kraków 2011, Ss. 129-130.

15 F. Bylok, Konsumpcja w Polsce i jej przemiany w okresie transformacji, Częstochowa 2005, s. 236.

16 Ibidem.

17 Traktuję tu terminy „moda” i „trend” synonimicznie, przy czym mowa tu o modzie w szerokim sensie, w przeciwieństwie do wąskiego, który ogranicza się do sfery ubioru. Por. A. Burgiel, Psychospołeczne prawidłowości zachowania się konsumentów, w: E. Kieżel (red.), Rynkowe zachowania konsumentów, Katowice 2000, s. 190. 
autorzy zajmujący się problematyką konsumpcji: Czesław Bywalec ${ }^{18}$, Felicjan Bylok ${ }^{19}$, Halina Jastrzębska-Smolaga ${ }^{20}$ ) czy też zielonej konsumpcji ${ }^{21}$.

Jak zauważa Geoffrey Miller, w przypadku jedzenia „organicznych muesli »Naturalna Ścieżka« z jedwabistym mlekiem sojowym”22 zaspokojenie głodu jest sprawą drugorzędną - liczy się funkcja dystynktywna konsumpcji tej żywności. Pozwala wyrazić przynależność do grona zwolenników ekologii, a zarazem odróżnić się od ludzi spożywających produkowane przez wielki koncern płatki „Kellogg’s Froste Flakes z mlekiem z farmy przemysłowej pełnym hormonów wzrostu”23, a więc, zdaniem tych pierwszych, zapewne pozbawionych wrażliwości ignorantów. Autor ten pisze, że „ostentacyjne zachowania proeko”24 stały się we współczesnych zachodnich społeczeństwach ważnym narzędziem gry o status. Świadczyć mają o wysokiej świadomości społecznej, trosce o przyrodę i dobrostan przyszłych pokoleń, odpowiedzialności, sumienności. Z kolei Anna Nacher, opisując kulturę nowego berlińskiego mieszczaństwa, zauważa, iż stanowi ono społeczność „dla której jednym z wyznaczników statusu staje się przestrzeganie zasad bycia w zgodzie z ekologią"25. Nic więc dziwnego, że w języku pojawiło się pojęcie „ekosnobizmu”.

W epoce późnej nowoczesności czy też ponowoczesności, których teoretycy osłabili eksplanacyjną moc pojęcia klasy społecznej, w tym jej wpływu na konsumpcję, to właśnie mody - mniej lub bardziej płynne, ulotne, obejmujące mniejsze lub większe segmenty społeczeństwa - w coraz większym stopniu wyznaczają kryteria dystynkcji ${ }^{26}$. Im - jak pisze Marek Krajewski - podporządkowana jest walka o wyróżnienie ${ }^{27}$. W nich więc szukać należy zewnętrznych wobec jednostek (kulturowych) determinant wyborów konsumpcyjnych. Nie oznacza to, że mody wyparły zapisaną

\footnotetext{
${ }^{18}$ C. Bywalec, L. Rudnicki, Konsumpcja, Warszawa 2002, s. 131.

${ }^{19}$ F. Bylok, Konsumpcja w Polsce..., s. 224.

${ }^{20}$ H. Jastrzębska-Smolaga, W kierunku trwałej konsumpcji, Warszawa 2000, s. 15.

${ }^{21}$ A. Neale, (Nie)przyjemności zielonego konsumeryzmu, ss. 115-142.

${ }^{22}$ G. Miller, Teoria szpanu..., s. 137.

${ }^{23}$ Ibidem.

${ }^{24}$ Ibidem, s. 324.

${ }^{25}$ A. Nacher, Rubieże kultury popularnej, ss. 173-174. Obraz tej społeczności przypomina przedstawioną wyżej burżuazyjną bohemę (bobo).

${ }^{26}$ Omawiana tu ekologia jest modą o szerokim zakresie, ale mody obejmować mogą także wąskie segmenty społeczeństwa, tworząc lokalne kryteria dystynkcji i hierarchie statusu. Zwykle im bardziej moda jest lokalna, tym większa jej dynamika, zmienność, ulot-

${ }^{27}$ M. Krajewski, Kultury kultury popularnej, Poznań 2005, s. 47.
} ność. 
w klasowej strukturze hierarchię. Ich rozwój prowadzi jednak do powstawania konkurencyjnych wobec niej hierarchii statusu - o różnym zakresie obowiązywania i czasie trwania. Hierarchia klasowa i narzucona przez modę mogą się uzupełniać. W takim wypadku, odnosząc się do omawianego przykładu, może zostać zachowana, w ramach jednej ekologicznej mody, odrębność wzorów konsumpcji klas wyższych i niższych.

Mody wyrastają spontanicznie ze społecznej tkanki bądź też inicjowane są w działach marketingu firm. Jednak nawet te powstałe żywiołowo są przechwytywane i sterowane przez rynek. Między oddolną praktyką społeczną a marketingiem zachodzi sprzężenie zwrotne - przykład ekologii dobrze ilustruje ten mechanizm. Sięgający korzeniami ideałów kontrkultury ${ }^{28}$, z czasem ogarniający coraz szersze rzesze społeczeństwa, styl życia w końcu wciągnięty został w tryby rynkowej machiny i reprodukowany jest pod postacią wyposażonego w odpowiednie statusowe konotacje komercyjnego ekotrendu, wspieranego przez ekomarketing ${ }^{29}$, znajdującego wyraz w ekokonsumpcji. Moda wytwarza konformizm - generuje wspólne dla objętych nią grup wzory konsumpcji ${ }^{30}$. Rozpoznanie, a jeszcze lepiej - kontrolowanie mód jest nader korzystne dla rynkowych graczy, ponieważ pozwala na lepsze przewidywanie potrzeb i wyborów konsumentów, a nawet ich kreowanie.

Taka diagnoza każe zrewidować teorię Pierre’a Bourdieu. Źródła dystynkcji nie mają tu bowiem charakteru wyłącznie, a nawet nie przede wszystkim klasowego, lecz w coraz większym stopniu związane są ze sterowanymi przez rynek modami. Jak pisze Krajewski:

Podstawą zróżnicowania społecznego w coraz mniejszym stopniu są [...] cechy wynikające z miejsca zajmowanego w strukturze klasowej i warstwowej, a w coraz większym stopniu te cechy, które zostały, jako podstawa dystynkcji, zaprojektowane przez specjalistów od reklamy ${ }^{31}$.

${ }^{28}$ T. Roszak, The Making of A Counter Culture, Berkeley 1995 (zwłaszcza: Introduction to the 1995 Edition).

${ }^{29}$ H. Bronakowski, Rynek - marketing dóbr i usług ekologicznych, Białystok 1997, s. 66 .

30 Oczywiście konformizmowi wobec określonej grupy towarzyszy chęć odróżnienia się od innej. Oba procesy - na co zwracał już uwagę Georg Simmel - stanowią o istocie mody. Sugestywnie ujmują to Joseph Heath i Andrew Potter: „Konformizm i wyróżnienie zawsze idą ręka w rękę - człowiek podporządkowuje się zwyczajom i standardom ekskluzywnego klubu, żeby się odróżnić od motłochu”. Zob. J. Heath, A. Potter, Bunt na sprzedaż. Dlaczego kultury nie da się zagłuszyć, Warszawa 2010, s. 158.

31 M. Krajewski, Konsumpcja i współczesność..., s. 22. 
Im bardziej rzeczywistość społeczna podporządkowana jest rynkowi, tym bardziej proces ten się nasila. Wizja, w której miejsce kultury prawomocnej w coraz większym stopniu przejmuje rynek, jest generalizacją obaw, jakie wyrażali postmarksistowscy krytycy konsumpcji ${ }^{32}$. W takim wypadku „prawomocne”, tzn. zapewniające społeczny prestiż, jest to, co zgodne z najnowszymi komercyjnymi trendami. Wszak już dziś „,bardzo często dany produkt staje się symbolem statusu ze względu na otoczkę symboliczną wytworzoną wokół niego przez speców od reklamy”33. Po prostu siła rynku w kreowaniu symboli statusu i autorytetu rośnie kosztem kulturowego kanonu ustalonego przez klasy dominujące i pielęgnowanego przez renomowane instytucje.

Taki właśnie obraz społeczeństwa wyłania się z książki Johna Seabrooka Nobrow - The Culture of Marketing, The Marketing of Culture ${ }^{34}$, w której argumentuje on, że rozróżnienie między gustem wysokim (high-brow) a niskim (low-brow) zostało zniesione, a źródłem hierarchii statusu stały się kreowane przez rynek mody.

Powyższe rozważania pozostawiają w mocy tezę, że w rzeczywistości społecznej na gruncie współczesnego kapitalizmu konsumpcja pełni funkcję dystynktywną. Jednakże kryteria owej dystynkcji narzucają generowane, a przynajmniej wzmacniane przez rynek, podlegające dynamicznym zmianom trendy. Jeśli przyjąć tę logikę, wskaźnikiem prestiżu przestaje być konsumpcja dzieł kanonicznej, wysokiej, uznanej za prawomocną kultury i względnie stałego, homologicznego wobec niej zbioru dóbr, a staje się konsumpcja reprezentujących - mniej lub bardziej efemeryczne - mody rekwizytów. Natomiast kapitał kulturowy wyraża się w umiejętności trafnego ich rozpoznawania, czujności i dobrej orientacji umożliwiającej szybką identyfikację nowych trendów i elastyczności pozwalającej na dostosowanie się do nich. Jak tłumaczy Aldona Jawłowska, dla współczesnych społeczeństw (czy też: społeczeństw postindustrialnych) charakterystyczna jest „zmienność, chwiejność, stały wyścig z samym sobą, by sprostać coraz to

${ }^{32}$ Pod pojęciem „postmarksizmu” rozumiem zachodnią myśli reinterpretującą Marksa na potrzeby krytyki zachodniego kapitalizmu, ale odrzucającą szereg fundamentalnych postulatów klasycznego marksizmu, np. postulat dotyczący uprzywilejowanej roli proletariatu; wpływową zwłaszcza w latach 60. i 70. XX wieku.

${ }_{33}$ Zob. K. Pietrowicz, Nasze gadżety codzienne albo o płynności symboli statusu, w: T. Szlendak, K. Pietrowicz (red.), Na pokaz - o konsumeryzmie w kapitalizmie bez kapitału, Toruń 2004, s. 71.

${ }^{34}$ J. Seabrook, Nobrow - The Culture of Marketing, the Marketing of Culture, New York 2001. 
nowym standardom doskonałości narzuconym przez rynek”35. Bourdieu twierdził, że „oko jest produktem historii reprodukowanym przez edukację"36 - na gruncie zaprezentowanej tu wizji należałoby sparafrazować to zdanie w następujący sposób: oko jest produktem mody reprodukowanym przez marketing i podporządkowaną mu popkulturę. A zatem kanon kulturowy w znaczeniu, jakie nadał mu autor Dystynkcji, zastępuje „kanon konsumpcyjnej wiedzy”; zamiast posiadającej zdobyty w toku formalnej edukacji wysoki poziom kapitału kulturowego jednostki pojawia się figura „doświadczonego konsumenta, wtajemniczonego i wymusztrowanego, zaprawionego w sztuce”37, takiego, który zdolny jest swą wiedzę nieustannie aktualizować. Jak wyjaśniał w jednym ze swych podręczników z połowy minionej dekady autorytet w dziedzinie marketingu, Philip Kotler:

Symbol statusu typowy dla Nowego Jorku to jogging, ryby i drób oraz chirurgia plastyczna dla mężczyzn; dla Chicago to zakupy z katalogów, rogalik francuski i taco oraz telefon w samochodzie; w San Francisco spadochroniarstwo, świeżo przygotowane spaghetti oraz koszule od Izoda ${ }^{38}$.

Ta lista dobrze pokazuje geograficzną zmienność, nietrwałość, ulotność symboli statusu we współczesnym świecie - dla statystycznego polskiego czytelnika znaczą one niewiele.

Charakterystyczną cechą mód jest ich zwykle mniejszy - w porównaniu z akumulowanym i reprodukowanym przez kolejne generacje kulturowym kanonem - społeczny zasięg oraz krótszy czas trwania. Nasycenie rynku powoduje, że cykl ich życia ulega dalszemu skracaniu i stają się one bardziej sfragmentaryzowane. „Trendy w kulturze i konsumpcji żyją coraz krócej, są coraz bardziej rozproszone, a przez to coraz trudniejsze w śledzeniu”39. Toteż - by odwołać się do słów Zygmunta Baumana:

[...] zasób wiedzy niezbędnej by nie wypaść z szeregu i nie zostać w tyle jest oszałamiający i przyprawia o zawrót głowy; niekończąca się lista nazwisk, marek, znaków fabrycznych i takaż lista tych, jakie należałoby z pamięci wymieść w miarę tego jak wciąż nowe zastępy idoli, wyroczni wzornictwa

${ }^{35}$ A. Jawłowska, Tożsamość na sprzedaż, w: A. Jawłowska (red.), Wokół problemów tożsamości, Warszawa 2001, s. 56.

${ }^{36}$ P. Bourdieu, Dystynkcja..., s. 11.

${ }^{37}$ Z. Bauman, Konsumenci w społeczeństwie konsumentów, w: Cykl wykładów dziekańskich: Gospodarka i społeczeństwo, Łódź 2007, s. 8.

${ }^{38} \mathrm{Ph}$. Kotler, Marketing. Analizowanie, planowanie, wdrażanie i kontrola, Warszawa 1994, s. 166.

${ }^{39}$ V. Makarenko, Tajne służby kapitalizmu, Kraków 2008, s. 153. 
i domów mody wyłaniają się jakby znikąd, szybko przemierzają skąpaną w świetle reflektorów i dźwiękach fanfar scenę, by za chwilę znów się w niebycie pogrążyć ${ }^{40}$.

\section{Natomiast Joseph Heath i Andrew Potter stwierdzają:}

Stąd te nieustanne fluktuacje na sporządzanych co miesiąc listach, które królują na pierwszych stronach [...] magazynów: in/out, hit/kit, dziś/wczoraj, kocham/szlocham, super/obciach [...] - nieważne co to jest, dopóki ludzie kupują więcej towarów ${ }^{41}$.

Obrońcy konserwatywnych, postulowanych przez Bourdieu hierarchii argumentować mogą, że taką perspektywę można odnieść wyłącznie do kultury popularnej, jednak trudno nie zauważyć, że dziś jej wzorce przenikają do wszelkich dziedzin życia społecznego ${ }^{42}$.

\section{Hipsterstwo}

Nie wszyscy autorzy zgadzają się, że kategoria mody pozwala skonceptualizować obowiązujące w dzisiejszej kulturze popularnej (zwłaszcza młodzieżowej) hierarchie statusu. Wspomniani wyżej Heath i Potter dla określenia „głównej hierarchii statusu we współczesnym społeczeństwie miejskim”43 używają słowa „cool” - podczas gdy „być cool” (o człowieku) to znajdować się na jej szczycie bądź (o przedmiocie konsumpcji) posiadać wysoką wartość statusową. Te same treści co „cool” wyraża słowo „hip”, są one traktowane synonimicznie ${ }^{44}$; natomiast człowiek będący „cool” to

40 Z. Bauman, Konsumenci w społeczeństwie konsumentów, s. 7.

41 J. Heath, A. Potter, Bunt na sprzedaż..., s. 238.

${ }^{42}$ Krajewski uważa, że kultura popularna jest dziś wszechobecna, stanowi kulturę dominującą - ,jej przejawy można odnaleźć w każdej sferze społecznego życia [...] jest podstawowym narzędziem, za pomocą którego potykamy się ze światem [...], w podporządkowanej swojej logice formie upowszechnia, kreuje ramy interpretacji rzeczywistości, sankcjonuje drogi jej poznawania i działania w jej obrębie [...], najważniejsza ze współczesnych map pozwalających poruszać się w splątanej rzeczywistości ponowoczesnych społeczeństw”. Zob. M. Krajewski, Kultury kultury popularnej, ss. 7, 10.

43 J. Heath, A. Potter, Bunt na sprzedaż..., s. 238.

44 O historii kategorii „,cool” i „hip”, ich zupełnie rozbieżnych źródłach i współczesnym utożsamieniu traktowało wystąpienie Joela Dinersteina w ramach konferencji „Is It Cause It's Cool? Affective Encounters with American Culture” (Salzburg, 4-6 listopada 2011 r.), zatytułowane Hip vs. Cool. Delineating Two Key Concepts of US Popular Culture. Jak pisze Piotr Siuda w sprawozdaniu z rzeczonej konferencji: „Zanik rozróżniania oby- 
„hipster”45. „Podobnie jak nie wszyscy mogą należeć do klasy wyższej i nie wszyscy mogą mieć dobry gust, nie każdy może być cool”46 - tłumaczą dalej autorzy. Pierwsza część zdania wskazuje na tradycyjną hierarchę statusu, jaką znajdujemy u Bourdieu, druga - tę obowiązującą we współczesnej miejskiej popkulturze.

Pojęcie hip (cool) nie zawsze było takie istotne dla naszej hierarchii statusu. Były czasy - dawno, dawno temu - kiedy dla Amerykanów bardziej liczyła się przynależność do klasy niż bycie cool [...] obecna hierarchia statusu nie jest związana z przynależnością klasową, ale z byciem cool ${ }^{47}$.

Czym różni się fenomen cool (czy też hipsterstwo - terminy te można traktować synonimicznie) od mody? Na to pytanie próbuje odpowiedzieć Heath w artykule The Structure of Hip Consumerism ${ }^{48}$. Utrzymuje on, że konsumpcja pełni funkcję dystynktywną, a określone wybory konsumpcyjne wiążą się z wysokim statusem. Jednocześnie kwestionuje - za Thomasem Frankiem - pogląd, iż u źródeł owych wyborów leży konformizm - czy to wobec trwałego kanonu kultury prawomocnej, czy też wobec narzucanych przez rynek mód. Dziś wysoki status manifestuje się nie poprzez konformizm, ale odróżnienie. Źródła tego stanu tkwią - jak twierdzi autor - w rewolucji kontrkulturowej. Ruchy kontrkulturowe lat 60 . odrzucały społeczny konformizm, uwznioślając indywidualizm, samorealizację. Wbrew intencjom ich twórców wartości te zaszczepione zostały w kulturowym mainstreamie i zagospodarowane przez rynek ${ }^{49}$. Rzecz jasna znalazły odbicie

dwu (terminów) stał się ewidentny w latach 70., kiedy to i hip, i cool stały się sloganami marketingowymi używanymi przez korporacje w celu zwiększenia sprzedaży. Utowarowienie obydwu wyrażeń sprzyjało ich zamiennemu użyciu i w końcu utożsamianiu”. Zob. P. Siuda, Cool czy nie cool, czyli jaka jest amerykańska kultura popularna? Sprawozdanie z konferencji naukowej „Is It Cause It's Cool? Affective Encounters with American Culture”, Salzburg, 4-6 listopada 2011, „Studia Medioznawcze” 2(49)/2012, s. 167.

${ }^{45}$ Historia kategorii hipstera sięga końca lat 40. i początkowo odnosiła się do znajdujących się poza głównym nurtem kultury Czarnych grających awangardę ówczesnego jazzu. W latach 70. została zaadaptowana przez język reklamy, jednak gwałtowny wzrost jej popularności nastąpił mniej więcej w końcu lat 90.

${ }^{46}$ J. Heath, A. Potter, Bunt na sprzedaż..., s. 238.

${ }^{47}$ Ibidem, ss. 241, 253.

48 J. Heath, The structure of hip consumerism, „Philosophy \& Social Criticism” 27(6)/ 2001, ss. 1-17.

${ }^{49}$ Sam Thomas Frank argumentuje, że rozwój kontrkultury i rynku od początku był sprzężony. Nie była to więc inkorporacja czy komercjalizacja jakiegoś czystego, nietkniętego przez komercję stylu życia, jak chcą widzieć to niektórzy postmarksistowcy myśliciele. Nie był to proces jednokierunkowy, polegający na tym, że idea kontrkulturowego 
na płaszczyźnie rywalizacji konsumpcyjnej - pożądane stało się nie tyle dopasowanie do określonej grupy, ile zaznaczenie swojej odmienności. Stąd - jak powiada Frank - buntownik wyrósł na centralną figurę współczesnej kultury konsumpcji ${ }^{50}$. Fenomen cool (hipsterstwa) to owoc tych procesów. Jest więc cool, po pierwsze, modą na kontestację, modą, która za wszelką cenę chce się wyzbyć aspektu konformizmu, a więc modą paradoksalną. Po drugie, na cool można spojrzeć jak na modę zaczarowaną (w sensie Weberowskim). O ile tradycyjnie pojęta moda jest zjawiskiem dającym się objąć pojęciowo, mającym określone granice, względnie czytelne kryteria, to cool jest fenomenem bardzo efemerycznym, wymykającym się kategoryzacjom, przez to magicznym; klarowne, możliwe do jednoznacznego zdefiniowania właściwości danego dobra, legitymizujące jego status jako modnego, tu zamieniają się w nieokreśloną aurę. Cool nieustannie musi wymykać się racjonalizacji i być owiane pewną tajemnicą - a taki status może zachować tylko, jeśli będzie podlegać ciągłej ewolucji, pozostanie niestabilne.

Istotny wpływ na spopularyzowanie pojęcia „cool” i rozwój dyskusji na jego temat we współczesnej kulturze i marketingu miał artykuł Malcolma Gladwella The Coolhunt z 1997 r. ${ }^{51}$ Istotę cool łączy autor z ulotną, niedefiniowalną charyzmą jednostek, które je uprawomocniają. Cool można raczej wyczuć niż zrozumieć. Zamknięcie cool w jakichś definicyjnych ramach pozbawia je mocy ${ }^{52}$. Jeśli zostaje uchwycone (i w konsekwencji określające je cechy ulegną utowarowieniu), dezaktualizuje się i odradza się pod postacią nowej hierarchii statusu.

Według Gladwella cool to coś abstrakcyjnego i nieokreślonego. Przypomina to słynną definicję dobra sformułowaną przez filozofa G.E. Moore’a - że jest to prosta, niedefiniowalna, mistyczna właściwość. Możemy to nazwać abstrakcyjno-esencjalistyczną wizją cool, w myśl której cool istnieje (są cool ludzie i cool rzeczy), choć większość z nas nigdy się nie dowie, na czym polega ${ }^{53}$.

Można by tu także sparafrazować słowa Susan Sontag na temat kampu, a zatem cool jest ezoteryczny, jest jakby prywatnym kodem, znamieniem

\footnotetext{
„buntu” została utowarowiona, rozkręcając rynek, lecz po części także zabiegi rynkowych graczy legły u podstaw kontrkultury.

${ }^{50}$ T. Frank, Alternative to what?, w: T. Frank, M. Weiland (red.), Commodify Your Dissent, New York 1997, s. 151; por. idem, The Conquest of Cool: Business Culture, Counterculture, and the Rise of Hip Consumerism, Chicago 1998.

${ }^{51}$ M. Gladwell, The Coolhunt, „The New Yorker” z 17.03.1997 r.

${ }^{52}$ A. Nacher, Rubieże kultury popularnej, s. 338.

53 J. Heath, A. Potter, Bunt na sprzedaż..., s. 237.
} 
tożsamości nawet niewielkich miejskich środowisk; mówić o cool to go zdradzać ${ }^{4}$.

Tyleż ironiczną, co trafną charakterystykę cool konsumenta (tu określonego mianem hipstera) można znaleźć w komentującym parodystycznie rzeczywistość serwisie internetowym Nonsensopedia. Oto jej fragmenty:

Hipster - odmiana człowieka. Jego cechy charakterystyczne są tak wyrafinowane, że nikt właściwie nie jest pewien, jak wyglądają. Za punkt honoru postawił sobie oryginalność. Tak oryginalny, że w skali oryginalności od 1 do 10 jest siedemnastką [...]. Ich [hipsterów - Ł.I.] środowiskiem jest tylko i wyłącznie miasto, gdzie indziej zginą z braku ekologicznej żywności i ciuchów z second-handu. Hipster przede wszystkim jest indywidualistą. Prawdziwy hipster nigdy nie skaleczył się komercją i brzydzi się tobą [...]. Hipsterzy mają właściwą sobie logikę, której używają do podkreślania swojej wyższości. Pierwszą rzeczą jest stwierdzenie: nie jestem hipsterem! Tak. Bycie hipsterem nie jest powodem do chluby ${ }^{55}$. Przede wszystkim jesteś wtedy zaszufladkowany. Hipsterzy tego nie lubią [...]. Drugą rzeczą jest ironia. Ironia jest ważną rzeczą w życiu hipstera. To jego tarcza przeciw normalnemu światu [...]. Kolejną rzeczą jest sztuka. Hipsterzy lubią sztukę, zwłaszcza sposób, w jaki na nią patrzą. Życiowym celem każdego hipstera jest polubienie czegoś, zanim stało się sławne ${ }^{56}$. Jeśli coś staje się znane,

54 S. Sontag, Notatki o kampie, „Literatura na Świecie” 9/1979, s. 307. Oryginalny tekst brzmi: „kamp jest ezoteryczny - jest jakby prywatnym kodem, znamieniem tożsamości nawet niewielkich miejskich środowisk [...] mówić o kampie to go zdradzać”.

55 Urban Dictionary podaje 328 definicji hipstera. Jak zauważa Nacher „w większości z nich znajdziemy podstawowe zastrzeżenie: aby być hipsterem, nie możesz nazwać się hipsterem (definicja nr 328), każdy kto nalega, że jest hipsterem, nie jest nim (definicja nr 324)”. A. Nacher, Rubieże kultury popularnej, s. 340. Autorka łączy taką postawę ze strategią odmowy tożsamości, która jawi się dziś jako jedyny sposób uniknięcia sformatowania przez rynek i utowarowienia. Ibidem, s. 358.

${ }^{56}$ W Internecie można napotkać związane z tą cechą - niekiedy przekraczające granice dobrego smaku - żarty, oparte na różnych wersjach sloganu „I knew before it was cool” (Znałem, zanim stało się cool), choćby na facebookowym profilu o nazwie „Łódź hipsterem miast”: http://www.facebook.com/lodz.hipsterem.miast [10.11.2015]. Jest tam m.in. zdjęcie Osamy Bin Ladena z podpisem „I knew abobut 9/11 before it was cool” czy też zdjęcie Antoniego Macierewicza z podpisem „I hated Tusk before it was cool” (Nienawidziłem Tuska, zanim stało się to cool). Z kolei jedna z ilustracji artykułu o hipsterach w „Gazecie Wyborczej” przedstawia papieża Franciszka I z podpisem „My name will be Francis, Benedict and John Paul are too mainstream” (Będę nazywać się Franciszek, Benedykt i Jan Paweł są zbyt mainstremowe): http://m.lodz.gazeta.pl/lodz/1,106512,13565071,Czy_ Lodz_jest_hipsterem_miast_html [10.11.2015]. Inne, krążące w Sieci żarty odwołujące się do przytoczonej tu charakterystyki hipstera: „wchodzi hipster do baru i mówi: ten bar jest do bani, jest pełen hipsterów”, czy - na portalu anglojęzycznym - zdjęcie smutnego hipstera z podpisem „sad hipster, just heard his favourite band on the radio” (smutny hipster, właśnie usłyszał swój ulubiony zespół w radiu). 
hipster odcina się od tego, bądź stwierdza: Lubiłem to, zanim było popularne!, powodując wstyd u komercyjnych przedstawicieli kultury masowej. Muzyka, obok lansu i ubioru, jest najważniejsza dla hipsterów [...]. Dlatego także tutaj należy płynąć pod prąd i myśleć za siebie. Z tego powodu najpopularniejsze wśród hipsterów są zespoły, które nie są popularne [...]. Bootleg ${ }^{57}$ wyszperany w jakimś oldskulowym ${ }^{58}$ sklepie z winylami ma bardzo wysoką wartość dla hipstera. Nawet jeśli zawiera tylko parę utworów, jedynych, jakie zespół wydał, a jego jakość pozostawia wiele do życzenia. Nie należy jednak się tym zespołem dzielić. Chyba że dojdzie do bitwy na zespoły, podczas której hipsterzy testują wzajemną znajomość undergroundowych ${ }^{59}$ zespołów. Dlatego też hipster musi znać historię muzyki bardzo dobrze, bo nieznajomość zespołu może skończyć się kompromitacją [...]. Mainstream to najczęściej używane przez hipsterów słowo jako synonim wszelkiego zła ${ }^{60}$.

Cool konsument (bądź hipster) na swój sposób (na miarę dzisiejszych czasów) kontynuuje tradycję dandyzmu. Dostatnie kapitalistyczne społeczeństwa kultywujące oryginalność - jakże funkcjonalną dla rynku w dobie kultu indywidualizmu i postmaterializmu - są wręcz idealnym gruntem dla rozwoju wrażliwości dandysa. „Dandys był przerysowany. Okazywał wzgardę lub znudzenie. Szukał rzadkich doznań, nieskalanych upodobaniami mas. [...] nienawidził pospolitości" ${ }^{61}$ - pisała Susan Sontag. Publicyści62 zwracają uwagę, że hipstera charakteryzuje wystudiowana nonszalancja ${ }^{63}$, poprzez swe ironiczne, estetyczne gry, zabawy konwencją pragnie on zamanifestować swą oryginalność, fetyszyzuje autentycznośćc4, ale stanowi jej zaprzeczenie, dowodząc jedynie wyczerpania się tej kategorii we współczesnej zachodniej (pop)kulturze ${ }^{65}$.

${ }^{57}$ Nielegalne, rozprowadzane poza oficjalnymi kanałami dystrybucji nagranie muzyczne.

${ }^{58}$ Od oldschool (ang.) - stary, w stylu retro; termin nacechowany pozytywnie.

${ }^{59}$ Od underground (ang.) - podziemny, nieznany szerszej publiczności.

${ }^{60} \mathrm{http}: / /$ nonsensopedia.wikia.com/wiki/Hipster [10.11.2014].

${ }^{61}$ S. Sontag, Notatki o kampie, s. 320.

${ }^{62}$ Należy wyjaśnić, że obok sylwetki hipstera charakteryzowanej w przedstawiony tu sposób w publicystyce pojawiają się także próby sprowadzenia hipsterstwa do kolejnej mody - opartej na konformizmie, wyrażającej się poprzez konkretne atrybuty, określone wzory konsumpcji. Nie o takie ujęcie jednak tu chodzi.

${ }^{63}$ D. Fletcher, Hipster, „Time” z 29.07.2009 r., http://www.time.com/time/arts/article/0,8599,1913220,00.html [10.11.2014].

${ }^{64}$ C. Lorentzen, Why the hipster must die, „Time Out New York” z 29.05.2007 r., http://newyork.timeout.com/things-to-do/this-week-in-new-york/8355/why-the-hipster-must-die [10.11.2014].

${ }_{65}$ D. Haddow, Hipster: The Dead End of Western Civilization, „Adbusters” z 29.08. 2008 r., http://www.adbusters.org/magazine/79/hipster.html?page=134 [10.11.2014]. 
Hipster - ktoś, kto posiada upodobania, postawy społeczne i poglądy uznane za cool przez tych, którzy są cool. Uwaga: nie zaleca się już używania określenia cool; hipster powiedziałby w takim przypadku, że coś jest deck ${ }^{66}$.

Anna Nacher wydobywa z tego - jakby nie patrzeć żartobliwego passusu, zaczerpniętego z Przewodnika po hipsterstwie - istotny dla naszych rozważań sens. Jak pisze:

[definicja ta - Ł.I.] odnosi się do faktu najbardziej charakterystycznego dla współczesnego hipsterstwa: szczególnej formy kapitału kulturowego polegającej na zdolności orientacji w szybko zmieniających się trendach, akcesoriach i drobiazgach, które decydują o tym, że coś jest deck [...]. A to z kolei zakłada bardzo czasem wysoki poziom kompetencji społecznych i zdolności oceny ${ }^{67}$.

Według Grahama Saxtona z zarządu MTV Europe cool to „gra, którą prowadzą dziś młodzi”; być cool to „być w temacie, kojarzyć o co chodzi”. A więc rozumieć środowiskowe kryteria prestiżu. Wśród konotacji tego terminu wskazuje: „alternatywny, niszowy”, ale także „snobistyczny, pozerski" ${ }^{68}$. Cool konsument pożąda zatem oryginalności, wyjątkowości, nie chce powielać trendu - jeśli już, to go wyprzedzać. Poprzez swe konsumpcyjne wybory stara się raczej pokazać, że jest niepowtarzalny, a nie modny. To ostatnie określenie dla cool konsumenta może wręcz brzmieć jak obelga. Jednak zdaniem Zygmunta Baumana tak naprawdę jest on do cna konformistyczny, lecz ten konformizm jest „wędrowny, w ciągłym ruchu, płynny i zmienny"69.

Cool rodzi się żywiołowo, a jego źródłem jest popkultura, ale działy marketingu współczesnych firm próbują go schwytać i zawłaszczyć. Świadczy o tym kariera pojęcia coolhuntingu, tj. prób wyławiania przez rynek owych cool, tak by rozpoznać dobra pełniące wśród konsumentów funkcje statusowe i móc je powielać w celach komercyjnych. Termin ten na dobre wszedł do słownika, także polskiego, marketingu i jest na gruncie tej dyscypliny coraz intensywniej dyskutowany i stosowany. Marketingowcy wiążą cool ze stylem życia jednostek określanych mianem innowatorów w znanym

${ }^{66}$ Według Urban Dictionary „deck” to hipsterskie określenie na coś, co jest „cool”: http://www.urbandictionary.com/define.php?term=deck [10.11.2014]. R. Lanham, The Hipster Handbook, New York 2003, podaję za: A. Nacher, Rubieże kultury popularnej, s. 341.

${ }^{67}$ A. Nacher, Rubieże kultury popularnej, s. 341.

${ }^{68}$ V. Makarenko, Tajne służby kapitalizmu, s. 144.

${ }^{69}$ Z. Bauman, Konsumenci w społeczeństwie konsumentów, s. 12. 
modelu rynkowej dyfuzji innowacji Everetta Rogersa ${ }^{70}$ (w nomenklaturze marketingowej nazywa się ich często także trendsetterami). Wierzą, że dostrzeżenie i przełożenie na konkretne produkty ich cech i zachowań to droga do rynkowego sukcesu, że konsumpcyjne wybory innowatorów - liderów hierarchii prestiżu - po jakimś czasie staną się konsumpcyjnymi wyborami mas. Jednak paradoks tego podejścia polega na tym, że uchwycenie, a tym bardziej próba sterowania, oraz przemysłowego reprodukowania atrybutów cool prowadzi do jego delegitymizacji. Ponadto dzisiejsza kultura stała się na tyle skomplikowana, a także rozproszona w najróżniejszych niszach, iż coraz trudniej zdobyć na jej temat kompleksową wiedzę, dokonać systematycznego wglądu i przewidzieć źródło oraz trajektorię i zasięg rozprzestrzeniania się oddolnych innowacji. Z tego właśnie powodu niektórzy autorzy podważają skuteczność coolhuntingu. Grant McCracken, znawca i autor wielu książek dotyczących współczesnej kultury popularnej i konsultant szeregu firm, wyrażał analogiczną opinię na swym blogu w poście zatytułowanym Who killed the cool hunter? ${ }^{71}$. Pęd współczesnej popkultury nie daje czasu na analizy, rozpoznania - kod cool odbiera się raczej intuicyjnie niż poznawczo. Umiejętność wyczucia go dostępna jest przede wszystkim tym, którzy go współtworzą - ale oni na pewno nie będą zainteresowani jego zdefiniowaniem, racjonalizacją (a tym samym odarciem z magicznej aury) i komercjalizacją.

A zatem niewątpliwie jednym z kluczowym wyzwań dla współczesnego rynku stała się umiejętność odkrycia cool, maskowanie swej roli w procesie jego reprodukowania, a zarazem zachowanie jego niedookreślonego, magicznego statusu. Operacja ta, jeśli w ogóle jest możliwa, nie może być podjęta z dystansu, wymaga wtopienia się w tkankę społeczną (taki rodzaj badania rynku określa się, także na gruncie polskim, mianem consumer immersion), a nade wszystko wyczucia jej pulsu i kolorytu, raczej swoistego kulturowego węchu niż racjonalnej analizy. Stąd rynkowi gracze odwołują się do coraz bardziej wyrafinowanych, utajonych strategii spod

${ }^{70}$ Model dotyczy nastawienia konsumentów wobec rynkowych nowości. Rogers wyszczególnił pięć grup: innowatorzy (ok. 2,5\% populacji, poszukujący nowości, skłonni do ryzyka), wcześni naśladowcy (ok. 13,5\% populacji, liderzy opinii), wczesna większość (ok. 34\% populacji - wcześnie absorbujący nowości), późna większość (ok. 34\% populacji - poszukują produktów oswojonych, sprawdzonych), maruderzy (ok. 16\% populacji - boją się zmian, niechętni wobec nowości). Zob. A. Pomykalski, Innowacje, Łódź 2001, ss. $113-114$.

${ }^{71}$ G. McCracken, Who killed the cool hunter?, http://cultureby.com/2006/06/who_ killed_the_html [10.11.2014]. 
znaku marketingu partyzanckiego czy wirusowego, a także operowania raczej niedopowiedzianą sugestią, wrażeniem niż jawną perswazją i mobilizacją.

Jakkolwiek autorzy (Joseph Heath i Andrew Potter, Malcolm Gladwell, Thomas Frank, Grant McCracken, Naomi Klein) podejmujący problematykę cool w kontekście hierarchii statusu posługują się publicystycznym, niekiedy mocno przejaskrawionym językiem, a w swych analizach dopuszczają się uproszczeń, przedkładając sugestywność wywodu nad jego głębięe (trudno zgodzić się z tak radykalną wizją reżimu cool, jaki kreślą, zaakceptować tezę, że stało się ono głównym źródłem społecznej hierarchii statusu), to niewątpliwie symptomy opisywanego przez nich zjawiska są dziś dostrzegalne. Dyktat cool obecny jest zwłaszcza na rynku młodzieżowym (analizy rzeczonych autorów dotyczą zresztą głównie tej właśnie kategorii społeczeństwa).

\section{Uwagi podsumowujące}

W artykule przyjęto, że status wyraża się (albo też jest tworzony) poprzez określone formy konsumpcji. Nasuwa się pytanie, czy konsumpcja jest jedynie wskaźnikiem statusu, czy też ten status sama kształtuje - innymi słowy: czy społeczna hierarchia jest pierwotna wobec konsumpcji, czy też przez konsumpcję kształtowana (oczywiście zawsze mamy do czynienia ze współzależnością obu wariantów, jednak pewne ujęcia silniej akcentują pierwszy, inne - drugi). W koncepcji Pierre'a Bourdieu status jest określony klasowo, a takie, a nie inne formy konsumpcji jedynie go biernie manifestują. A zatem kryteria prestiżu są uniwersalne i pierwotne wobec konsumpcji, zakodowane w ustrukturyzowanej klasowo kulturze. Nawet gdy konsument zna obowiązujące kryteria statusu, a więc konsumpcja staje się świadomie kształtowaną w celach autoprezentacji aktywnością, i tak ostatecznie dąży on do sprostania wpisanym w strukturę kryteriom statusu. Późniejsze, zwłaszcza postmodernistyczne, ujęcia osłabiły znaczenie klasy w wyznaczaniu hierarchii statusu, wskazując na rolę rynkowych mód, jak i różnych kulturowych czynników (co jest wynikiem procesu, który Daniel Bell opisuje jako „napaść kultury na strukturę społeczną”72). W tej optyce prestiż nie jest oparty wyłącznie na klasowo ufundowanym kapitale, ale w większym stopniu na względnie niezależnym od niego rozeznaniu obo-

\footnotetext{
${ }^{72}$ D. Bell, Kulturowe sprzeczności kapitalizmu, Warszawa 1998, s. 89.
} 
wiązujących trendów. To właśnie miał na myśli Zygmunt Bauman, mówiąc, że dyktowany przez klasy dominujące kanon został zastąpiony przez „kanon konsumpcyjnej wiedzy"73. Zdaniem Marka Krajewskiego to konsumpcja sama w sobie staje się czynnikiem dającym prestiż. Jak pisze: „Status, pozycja społeczna jednostki nie tylko są manifestowane przez styl życia [a tym samym formy konsumpcji - Ł.I.], ale również od niego zależą"74. A gdzie indziej tłumaczy, iż konsumpcja nie jest już (jak ma to miejsce w przypadku Bourdieu) ,,postrzegana przede wszystkim jako konsekwencja czy derywacja istotniejszych procesów strukturyzacyjnych”. Dziś - jak powiada -,,upodmiotawia się” i sama tworzy hierarchie statusu75. Co więcej, w realiach relatywizującego się społeczeństwa coraz trudniej uchwycić jedną uniwersalną hierarchię statusu - status w szerokim sensie rozumiemy jako „ogólną pozycję społeczną”, opartą na jakichś obiektywnych, jednoznacznych kryteriach ${ }^{76}$-a trzeba raczej mówić o wielu, przypisanych do różnych środowisk i ról, nieustannie zresztą ewoluujących, ulotnych hierarchiach. Kulturowo uwarunkowane kryteria prestiżu mogą być związane zarówno ze znajomością obowiązującej mody, jak i nisz, swoistym wtajemniczeniem (hipsterstwo). Zwolennicy klasowej wizji społeczeństwa mogą argumentować, że prestiż nie jest całkiem niezależny od czynników klasowych - choćby w takim sensie, że osoby o wyższym kapitale mają większą szansę być na bieżąco z owymi „kanonami wiedzy konsumpcyjnej”, jak i rozpoznawać, śledzić wszelkiego typu nowo powstające kryteria prestiżu i realizować ich zalecenia czy też bardziej ostentacyjnie prezentować swą indywidualność. Niemniej zdaniem wielu autorów to konsumpcji przyznana tu zostaje pierwotna rola, konsumpcja sama w sobie staje się czynnikiem nadającym prestiż. Krajewski pisze, iż „konsumpcja [...] stała się jedną z istotniejszych podstaw strukturyzacji wspólnot”, a unieważnieniu ulegają „dystynkcje osadzone w strukturze klasowej, warstwowej czy zawodowej"”7.

\section{Literatura}

Bauman Z., Konsumenci w społeczeństwie konsumentów, w: idem, Cykl wykładów dziekańskich: Gospodarka i społeczeństwo, Łódź 2007.

Bell D., Kulturowe sprzeczności kapitalizmu, Warszawa 1998.

\footnotetext{
${ }^{73}$ Z. Bauman, Konsumenci w społeczeństwie konsumentów, s. 8.

${ }^{74}$ M. Krajewski, Kultury kultury popularnej, s. 47.

${ }^{75}$ M. Krajewski, Konsumpcja i współczesność..., s. 22.

${ }^{76}$ H. Domański, Prestiż, Toruń 2012, s. 20.

77 M. Krajewski, Konsumpcja i współczesność..., s. 9.
} 
Bosacka K., Bracia od czekolady i siostry od sera, „Wysokie Obcasy” z 12.07.2009 r., http:// www.wysokieobcasy.pl/wysokie-obcasy/1,80530,6806589.html [10.11.2014].

Bourdieu P., Dystynkcja. Społeczna krytyka władzy sqdzenia, Warszawa 2005.

Bronakowski H., Rynek - marketing dóbr i usług ekologicznych, Białystok 1997.

Brooks D., Bobos in Paradise: The New Upper Class and How They Got There, New York 2000.

Burgiel A., Psychospołeczne prawidłowości zachowania się konsumentów, w: E. Kieżel (red.), Rynkowe zachowania konsumentów, Katowice 2000.

Bylok F., Konsumpcja w Polsce i jej przemiany w okresie transformacji, Częstochowa 2005.

Bywalec C., Rudnicki L., Konsumpcja, Warszawa 2002.

Domagalska K., Ekolodzy schodzq z drzew, „Wysokie Obcasy” z 7.13.2010 r., http://www. wysokieobcasy.pl/wysokie-obcasy/1,80530,8116701,Ekolodzy_schodza_z_drzew. html [10.11.2014].

Domański H., Prestiż, Toruń 2012.

Fletcher D., Hipster, „Time” z 29.07.2009 r., http://www.time.com/time/arts/article/0,8599,1913220,00.html [10.11.2014].

Frank T., Alternative to what?, T. Frank, M. Weiland (red.), Commodify Your Dissent, New York 1997.

Frank T., The Conquest of Cool: Business Culture, Counterculture, and the Rise of Hip Consumerism, Chicago 1998.

Gladwell M., The Coolhunt, „The New Yorker” z 17.03.1997 r.

Haddow D., Hipster: The Dead End of Western Civilization, „Adbusters” z 29.08.2008 r., http://www.adbusters.org/magazine/79/hipster.html?page=134 [10.11.2014].

Heath J., The structure of hip consumerism, „Philosophy \& Social Criticism” 27(6)/2001.

Heath J., Potter A., Bunt na sprzedaż. Dlaczego kultury nie da się zagłuszyć, Warszawa 2010.

Jastrzębska-Smolaga H., W kierunku trwałej konsumpcji, Warszawa 2000.

Jawłowska A., Tożsamość na sprzedaż, w: A. Jawłowska (red.), Wokół problemów tożsamości, Warszawa 2001.

Kotler Ph., Marketing. Analizowanie, planowanie, wdrażanie i kontrola, Warszawa 1994.

Krajewski M., Konsumpcja i współczesność. O pewnej perspektywie rozumienia świata społecznego, „Kultura i Społeczeństwo” 3/1997.

Krajewski M., Kultury kultury popularnej, Poznań 2005.

Lorentzen C., Why the hipster must die, „Time Out New York” z 29.05.2007 r., http://newyork.timeout.com/things-to-do/this-week-in-new-york/8355/why-the-hipster-must-die [10.11.2014].

Makarenko V., Tajne służby kapitalizmu, Kraków 2008.

McCracken G., Who killed the cool hunter?, 2006, http://cultureby.com/2006/06/who_killed_the_html [10.11.2014].

Miller G., Teoria szpanu. Seks ewolucja i zachowanie klienta, Warszawa 2010.

Nacher A., Rubieże kultury popularnej, Kraków 2012.

Neale A., (Nie)przyjemności zielonego konsumeryzmu, w: K. Romaniszyn (red.), Nowa droga do zniewolenia. O życiu w społeczeństwie konsumpcyjnym, Kraków 2011.

Pietrowicz K., Nasze gadżety codzienne albo o płynności symboli statusu, w: T. Szlendak, K. Pietrowicz (red.), Na pokaz - o konsumeryzmie w kapitalizmie bez kapitału, Toruń 2004. 
Pomykalski A., Innowacje, Łódź 2001.

Roszak T., The Making of A Counter Culture, Berkeley 1995.

Seabrook J., Nobrow - The Culture of Marketing, the Marketing of Culture, New York 2001. Siuda P., Cool czy nie cool, czyli jaka jest amerykańska kultura popularna? Sprawozdanie $z$ konferencji naukowej „Is It 'Cause It's Cool? Affective Encounters with American Culture”, Salzburg, 4-6 listopada 2011, „Studia Medioznawcze” 2(49)/2012.

Sontag S., Notatki o kampie, „Literatura na Świecie” 9/1979.

Veblen T., Teoria klasy próżniaczej, Warszawa 2008.

http://edunews.pl/index.php?option=com_content\&task=view\&id=904\&Itemid=16 [10.11. 2014].

http://m.lodz.gazeta.pl/lodz/1,106512,13565071,Czy_Lodz_jest_hipsterem_miast_html [10.11.2014].

http://nonsensopedia.wikia.com/wiki/Hipster [10.11.2014]. http://www.facebook.com/lodz.hipsterem.miast [10.11.2014].

http://www.firma.egospodarka.pl/43423,Czy-zywnosc-ekologiczna-rozni-sie-od-zwyklej,1,11,1.html [10.11.2014]. http://www.jolankom.pl.tl/ [10.11.2014]. http://www.organicmarket.pl/spoka.html [10.11.2014]. http://www.urbandictionary.com/define.php?term=deck [10.11.2014]. http://www.zielonebiuro.com/ [10.11.2014]. 